\title{
A study on the estimation and prediction of volatility on financial assets
}

\author{
Chang-Ho $\mathrm{An}^{1} *$ \\ ${ }^{l}$ Department of Financial Information Engineering, Seokyeong University, 124 Seokyeong-ro, Seongbuk-gu, Seoul 02713, Korea \\ *Corresponding author E-mail:choan@skuniv.ac.kr
}

\begin{abstract}
Volatility in financial markets due to changes in the internal and external financial market environment causes economic entities to increase uncertainty of economic activity, thus affecting the real economy. The volatility of stock index, interest rate, and exchange rate has a negative impact on the business performance of companies and financial institutions due to decline in the value of stocks, bonds, and derivatives held for short-term trading purposes. In this study, therefore, the KRW/USD exchange rate and the KOSDAQ index data from January 2005 to December 2017 were converted to log yield data for volatility estimation. Autocorrelation test of the error terms confirmed the partial autocorrelation function, and a Portmanteau Q-test was performed. Significant parameters were estimated by the stepwise autoregressive method. The Lagrange Multiplier test (L-M test) was used for the ARCH effect and the order of the model, and parameters were estimated by the Maximum Likelihood Method. Fit of the estimated model was found to follow the white noise according to the Portmanteau Q-test using standardized residuals. As the result, AR(1,2,3,13)-ARCH(1) model was selected as the volatility estimation model for KRW/USD exchange rate, and AR(1)-ARCH(1) model for KOSDAQ index.
\end{abstract}

Keywords: Log yield, Volatility, Portmanteau-Q test, Lagrange Multiplier test, $A R(p)-A R C H(q)$

\section{Introduction}

The international financial market has been rapidly cooled as the US sovereign credit rating has been downgraded, and since then has remained unstable due to the worsening European debt crisis and concerns over China's shortage of money. Global financial markets are highly volatile due to concerns over spread of the European financial crisis and the slowing US economy, which is reinforcing the preference for safe financial assets. The volatility of Korean financial market is also increasing after the global financial crisis. The volatility of financial market due to changes in the internal and external financial market environment can affect the real economy by increasing uncertainty of the economic activity from the macroeconomic viewpoint. For example, if the volatility of stock index expands, uncertainty in corporate financing tends to disrupt future investment plans. The volatility of exchange rate can be a factor to reduce international trade volume by distorting the relative price system at home and abroad, and can make uncertainty on profitability of companies increased. From the microeconomic viewpoint, volatility in stock prices, interest rates, and exchange rates has a negative impact on the performance of companies and financial institutions due to decline in the value of stocks, bonds, and derivatives, which are securities held for short-term trading purposes. Therefore, it is necessary to estimate and forecast volatility by minimizing uncertainty of economy in a macroeconomic framework, and through risk management that reflects risks from price fluctuations in advance in a microeconomic framework. The volatility of financial assets has been studied over a long period of time. Anderson \& Bollerslov (1998) estimated volatility using the daily rate of return on exchange rate and compared the predictive power of estimates obtained through the GARCH model using the 5-minute rate of return [1]. Akgiray
(1989) showed that the GARCH model was superior to the ARCH and EWMA model in predicting US stock index volatility [2], Jorion (1995) studied usefulness of information on the future realization volatility of foreign exchange options [3], and Ghysels et al. (2003) showed that absolute returns were superior to squared returns in predicting volatility using DM/USD returns [4]. Xiao and Aydemir (2007) compared various modified GARCH models using daily yield data [5]. Kim \& Kwon (2011) developed a forecasting algorithm for the exchange rate confidence interval during the economic crisis [6]. Kim \& Kim (2012) studied fit of the time series model for the KRW/USD exchange rate [7]. Kim (2013) analyzed the volatility of KRW/CNY, KRW/USD, and KRW/JPY exchange rates using the FIGARCH model, the GJR model, and the EGARCH model [8]. Jang (2013) conducted an exploratory data analysis on the Korean exchange rate through a recurrence plot [9], Kwon \& Lee (2014) analyzed the KOSPI200 futures, which are time series data similar to exchange rate, using the VECM and GARCH models [10], and Lee \& Chun (2016) predicted the volatility of CNY using the deep learning [11]. In this study, volatility was estimated and predicted by the AR(p)$\operatorname{ARCH}(\mathrm{q})$ model, which is an autoregressive conditional heteroscedasticity model, using the log yield data of the KRW/USD exchange rate and the KOSDAQ index.

\section{Research method}

\subsection{Data conversion}

Data used for this study are the KRW/USD rate and KOSDAQ index from 2005 to 2017 provided by the Korea Economic Statistics System (ECOS). In order to estimate the volatility of financial assets, the original data was convert to the log yield data as shown 
in (Equation 1) to provide financial phenomenon information with more return data than the original data and to solve the asymmetric problem of probability distribution. When value of the financial asset at time $t$ is $Z_{t}$,

$\mathrm{R}_{\mathrm{t}}=\frac{\mathrm{Z}_{\mathrm{t}}-\mathrm{Z}_{\mathrm{t}-1}}{\mathrm{Z}_{\mathrm{t}-1}}=\ln \frac{\mathrm{Z}_{\mathrm{t}}}{\mathrm{Z}_{\mathrm{t}-1}}$

is the $\log$ yield of the asset occurred in period $[t-1, t]$.

\subsection{Volatility model}

The model for estimating the volatility of financial assets is divided into two models: the ARCH (Autoregressive Conditional Heteroscedasticity) model and the GARCH (Generalized ARCH) model. The ARCH model is a seemingly unrelated regression model at $v_{\mathrm{t}}$, but the present value of $v_{\mathrm{t}}$, is affected by the quadratic form of past values (Equation 2) [12].

$\mathrm{y}_{\mathrm{t}}=\mathbf{X}_{\mathrm{t}}^{\prime} \boldsymbol{\beta}+\varepsilon_{\mathrm{t}}$

$\varepsilon_{\mathrm{t}}=\phi_{1} \varepsilon_{\mathrm{t}-1}+\cdots+\phi_{\mathrm{p}} \varepsilon_{\mathrm{t}-\mathrm{p}}+v_{\mathrm{t}}$

$v_{\mathrm{t}}=\sigma_{\mathrm{t}} \mathrm{a}_{\mathrm{t}}$

$\sigma_{\mathrm{t}}^{2}=\alpha_{0}+\alpha_{1} v_{\mathrm{t}-1}^{2}+\cdots+\alpha_{q} v_{\mathrm{t}-\mathrm{q}}^{2}$

where $a_{t} \sim N(0,1)$ (a white noise), and $\sigma_{t}^{2}$ is a variance in the model, so $\alpha_{0}>0, \alpha_{i} \geq 0, i=1, \cdots, p$ must be satisfied in order to have a positive value. When the volatility $\sigma_{t}^{2}$ follows the ARCH model, $\sigma_{\mathrm{t}}^{2}$ becomes larger as the past impact $\left(v_{\mathrm{t}-1}, \cdots, v_{\mathrm{t}-\mathrm{q}}\right)$ becomes larger, which also means a larger current impact $\left(v_{t}\right)$ due to $v_{\mathrm{t}}=\sigma_{\mathrm{t}} \mathrm{a}_{\mathrm{t}}$. And the GARCH model is a model proposed to overcome the problem of efficiency decrease due to increase of the number of parameters in the ARCH model (Equation 3) [13]. In the (Equation 2), if $\sigma_{\mathrm{t}}^{2}=\alpha_{0}+\alpha_{1} v_{\mathrm{t}-1}^{2}+\cdots+\alpha_{q} v_{\mathrm{t}-\mathrm{q}}^{2}$ is modified as

$\sigma_{\mathrm{t}}^{2}=\alpha_{0}+\sum_{\mathrm{i}=1}^{\mathrm{p}} \alpha_{\mathrm{i}} v_{\mathrm{t}-\mathrm{i}}^{2}+\sum_{\mathrm{j}=1}^{\mathrm{q}} \delta_{\mathrm{j}} \sigma_{\mathrm{t}-\mathrm{j}}^{2}$

$\sigma_{\mathrm{t}}^{2}$ follows the $\operatorname{GARCH}(\mathrm{p}, \mathrm{q})$ model. The $\operatorname{GARCH}(0, q)$ model is the ARCH(q) model, where $\mathrm{a}_{\mathrm{t}} \sim \mathrm{N}(0,1)$ (a white noise), and $\sigma_{\mathrm{t}}^{2}>0$, so $\alpha_{0}>0, \alpha_{i} \geq 0, \delta_{j} \geq 0, \quad \sum_{i=1}^{p} \alpha_{i}+\sum_{j=1}^{q} \delta_{j}<1$ must be satisfied.

\subsection{Model-setting and diagnosis}

The method of estimating and predicting the volatility model using the $\log$ yield data is generally as follows.

[Procedure 1] Set up an autoregressive model for the error terms. [Procedure 2] Perform additional autocorrelation tests on residuals. [Procedure 3] Understand the volatility of variance of error term and set up the model.

[Procedure 4] Diagnose the model and forecast.

In procedures 1 and 2, the partial autocorrelation function (PACF) or the Portmanteau Q-statistic is used to test the autocorrelation of the error term. In procedure 3 , the presence of heteroscedasticity of the error term is determined using the Portmanteau Q-statistic or the Lagrange Multiplier Test (LM-statistic) [14]. If there is a conditional heteroscedasticity, the order of the ARCH model is set to $\mathrm{q}$ when $\mathrm{LM}_{\mathrm{q}+1}-\mathrm{LM}_{\mathrm{q}}$ is no longer significant by using the fact that $\mathrm{LM}_{\mathrm{q}+1}-\mathrm{LM}_{\mathrm{q}}$ approximates the $\chi_{\alpha}^{2}(1)$ distribution among the orders until the LM-statistic value is significant [15]. When the ARCH effect is significant and the order of the model is determined, the parameter is estimated by the maximum likelihood estimation method. Then the model is diagnosed to predict the volatility of financial assets using the Portmanteau Q-statistic to determine whether the autocorrelation exists in the residual obtained after model fitting.

\section{Results}

\subsection{Volatility clustering}

After converting the exchange rate and KOSDAQ index data to $\log$ yield data and reviewing the movement of second moment, Figures 1 and 2 show the volatility clustering tendency. This means that autocorrelation exists in the error terms.

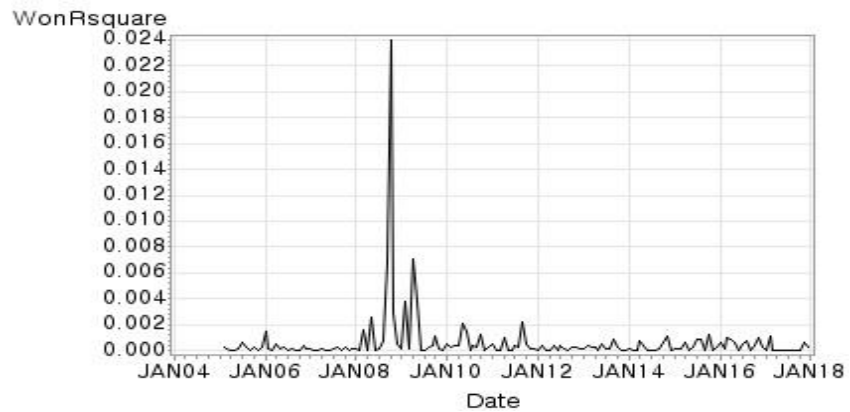

Fig. 1: Log yield square (exchange rate) time plot

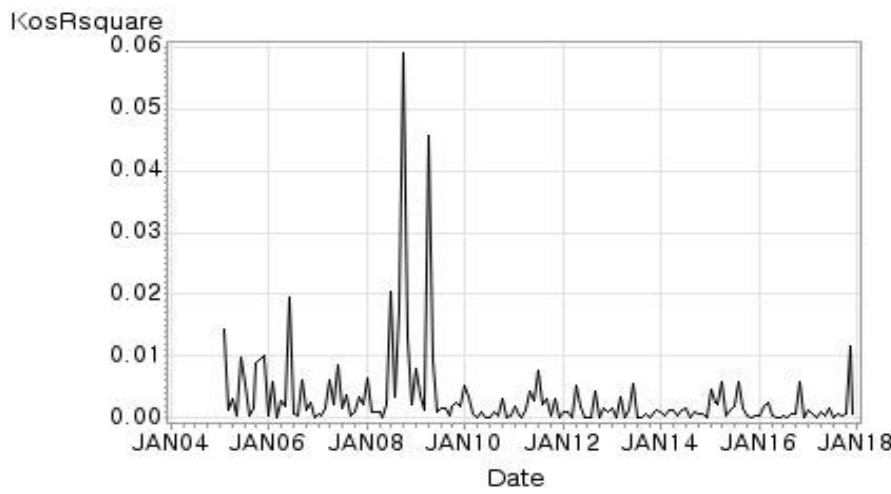

Fig. 2: Log yield square (KOSDAQ index) time plot

\subsection{Autocorrelation and conditional heteroscedasticity test of the error term $\varepsilon_{t}$}

Autocorrelation test using the Portmanteau Q-test of log yield (exchange rate, KOSDAQ index) was significant in all time lags. Partial autocorrelation test using PACF of the log yield of exchange rate was significant up to the time lag 13, and KOSDAQ index up to the time lag 5 . In order to test whether there is additional autocorrelation in the residuals of the model with 13th and 5th order autocorrelation, we performed the Portmanteau Q-test using $\widehat{v_{\mathrm{t}}}$. As the result, there was no autocorrelation at the significance level $\alpha=0.05$. As shown in Table 1 .

Table 1: Autocorrelation test

Autocorrelation Check for White Noise

\begin{tabular}{|c|c|c|c|c|c|c|c|}
\hline \multicolumn{8}{|c|}{ Autocorrelation Check for White Noise } \\
\hline \multicolumn{7}{|c|}{ Log yield (exchange rate) } & \multicolumn{4}{c|}{ Log yield (KOSDAQ index) } \\
\hline Lag & ChiSq & DF & P $>$ Chisq & Lag & ChiSq & DF & P $>$ Chisq \\
\hline 6 & 2.57 & 6 & 0.8610 & 6 & 11.90 & 6 & 0.0641 \\
\hline 12 & 10.35 & 12 & 0.5852 & 12 & 15.19 & 12 & 0.2314 \\
\hline 18 & 12.20 & 18 & 0.8368 & 18 & 25.08 & 18 & 0.1227 \\
\hline 24 & 20.48 & 24 & 0.6691 & 24 & 28.43 & 24 & 0.2424 \\
\hline
\end{tabular}

Also, autocorrelation test using Portmanteau Q-test of $\widehat{v_{\mathrm{t}}^{2}}$, square of the residuals obtained from the autoregressive model of the error terms, was found to be significant at all time lags 1 to 12 , at the significance level $\alpha=0.05$. This indicated that there was the ARCH effect. Therefore, ARCH(q) model of log yield (exchange rate) using the LM-statistic was set to the $\mathrm{ARCH}(1)$ model because $\mathrm{LM} 2-\mathrm{LM} 1=0.3933<\chi_{0.05}^{2}(1)=3.841$ as shown in Table 2, 
and $\mathrm{ARCH}(\mathrm{q})$ model of log yield (KOSDAQ index) was set to the $\mathrm{ARCH}(1)$ model because LM2-LM1 $=0.02<\chi_{0.05}^{2}(1)=3.841$.

Table 2: Conditional heteroscedasticity test

\begin{tabular}{|c|c|c|c|c|}
\hline & \multicolumn{2}{|c|}{ Log yield (exchange rate) } & \multicolumn{2}{c|}{ Log yield (KOSDAQ index) } \\
\hline Order & LM & Pr $>$ LM & LM & Pr > LM \\
\hline 1 & 15.9352 & $<.0001$ & 10.3972 & 0.0013 \\
\hline 2 & 16.3285 & 0.0003 & 10.4172 & 0.0055 \\
\hline 3 & 16.3305 & 0.0010 & 16.2328 & 0.0010 \\
\hline 4 & 18.3353 & 0.0011 & 16.7854 & 0.0021 \\
\hline 5 & 18.5944 & 0.0023 & 16.8095 & 0.0049 \\
\hline 6 & 24.9429 & 0.0003 & 33.5643 & $<.0001$ \\
\hline 7 & 25.7799 & 0.0006 & 33.6883 & $<.0001$ \\
\hline 8 & 27.2992 & 0.0006 & 33.8090 & $<.0001$ \\
\hline 9 & 27.3108 & 0.0012 & 34.1245 & $<.0001$ \\
\hline 10 & 28.1250 & 0.0017 & 34.6819 & 0.0001 \\
\hline 11 & 28.1661 & 0.0031 & 34.6964 & 0.0003 \\
\hline 12 & 28.2345 & 0.0051 & 38.8424 & 0.0001 \\
\hline
\end{tabular}

Also, the $\operatorname{AR}(1,2,3,13)$ model was estimated by the stepwise autoregressive method except for the insignificant parameters in log yield (exchange rate) following the AR(13) model, and the $\mathrm{AR}(1)$ model was estimated in log yield (KOSDAQ index) following the AR(5) model.

\subsection{Model fit and diagnosis}

The results of estimating the parameters that fit the $\operatorname{AR}(1,2,3,13)$ $\mathrm{ARCH}(1)$ model for $\log$ yield (exchange rate) and the AR(1)ARCH(1) model for log yield (KOSDAQ index) were all significant at the various significance levels as shown in Table 3.

Table 3: Model fit

\begin{tabular}{|c|c|c|c|c|c|}
\hline \multicolumn{7}{|c|}{ Log yield (exchange rate) } \\
\hline \multicolumn{7}{|c|}{ Parameter Estimates } \\
\hline Variable & DF & Estimate & S.E & T Value & Pr $>|t|$ \\
\hline AR1 & 1 & -0.4634 & 0.1117 & -4.15 & $<.0001$ \\
\hline AR2 & 1 & 0.3787 & 0.0697 & 5.43 & $<.0001$ \\
\hline AR3 & 1 & -0.1930 & 0.0583 & -3.31 & 0.0009 \\
\hline AR13 & 1 & 0.2119 & 0.0495 & 4.28 & $<.0001$ \\
\hline ARCH0 & 1 & 0.000301 & 0.0000441 & 6.83 & $<.0001$ \\
\hline ARCH1 & 1 & 0.2860 & 0.0833 & 3.43 & 0.0006 \\
\hline \multicolumn{7}{|c|}{ Log yield (KOSDAQ index) } \\
\hline AR1 & 1 & -0.3058 & 0.0909 & -3.36 & 0.0008 \\
\hline ARCH0 & 1 & 0.002440 & 0.000260 & 9.37 & $<.0001$ \\
\hline ARCH1 & 1 & 0.2067 & 0.0440 & 0.85 & 0.0428 \\
\hline
\end{tabular}

As a result of the autocorrelation test after model fitting, it was judged that there was no more autocorrelation at the significance level $\alpha=0.05$ as shown in Table 4 .

Table 4: Autocorrelation after fitting model Autocorrelation Check for White Noise

\begin{tabular}{|c|c|c|c|c|c|c|c|}
\hline \multicolumn{8}{|c|}{ Autocorrelation Check for White Noise } \\
\hline \multicolumn{3}{|c|}{ Log yield (exchange rate) } & \multicolumn{4}{|c|}{ Log yield (KOSDAQ index) } \\
\hline Lag & ChiSq & DF & P>Chisq & Lag & ChiSq & DF & P $>$ Chisq \\
\hline 6 & 2.33 & 6 & 0.8865 & 6 & 10.60 & 6 & 0.1014 \\
\hline 12 & 12.75 & 12 & 0.3877 & 12 & 14.25 & 12 & 0.2850 \\
\hline 18 & 16.64 & 18 & 0.5418 & 18 & 25.29 & 18 & 0.1172 \\
\hline 24 & 22.59 & 24 & 0.5442 & 24 & 28.74 & 24 & 0.2302 \\
\hline
\end{tabular}

Therefore, the final estimated $\mathrm{AR}(1,2,3,13)-\mathrm{ARCH}(1)$ model of the log yield (exchange rate) data is as shown in (Equation 4),

$\widehat{\varepsilon_{\mathrm{t}}}=0.4634 \widehat{\varepsilon_{\mathrm{t}-1}}-0.3787 \widehat{\varepsilon_{\mathrm{t}-2}}+0.1930 \widehat{\varepsilon_{\mathrm{t}-3}}-0.2119 \widehat{\varepsilon_{\mathrm{t}-13}}+$ $\widehat{v_{\mathrm{t}}}$

$\widehat{v_{\mathrm{t}}}=\widehat{\sigma_{\mathrm{t}}} \mathrm{a}_{\mathrm{t}}$

$\widehat{\sigma_{\mathrm{t}}^{2}}=0.000301+0.2860 \widehat{v_{\mathrm{t}}^{2}}$

and the AR(1)-ARCH(1) model of the log yield (KOSDAQ index) data in (Equation 5).

$\widehat{\varepsilon_{\mathrm{t}}}=0.3058 \widehat{\varepsilon_{\mathrm{t}-1}}+\widehat{v_{\mathrm{t}}}$ $\widehat{v_{t}}=\widehat{\sigma}_{t} a_{t}$

$\widehat{\sigma_{\mathrm{t}}^{2}}=0.002440+0.2067 \widehat{v_{\mathrm{t}}^{2}}$

And the $95 \%$ confidence interval and the predicted values using the estimated models are shown in Figures 3 and 4. In each figure, the solid line (blue) shows the 95\% confidence interval and the dotted line (red) shows the predicted values.

Wonhat

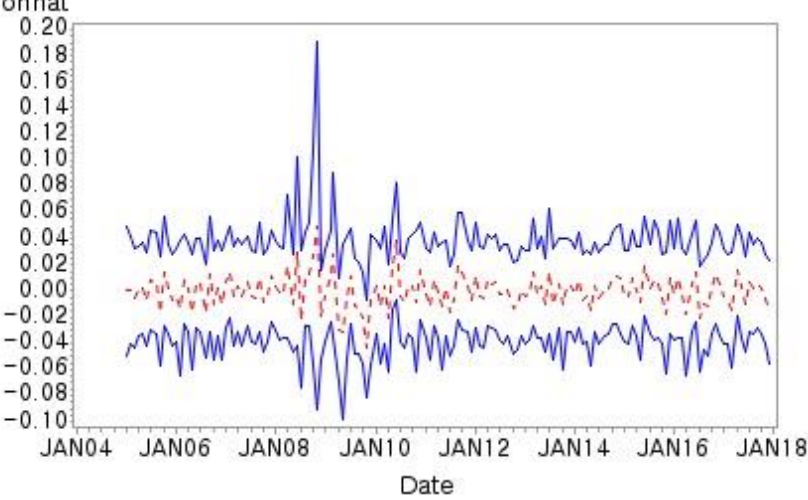

Fig. 3: 95\% Confidence interval and forecast of log yield (exchange rate)

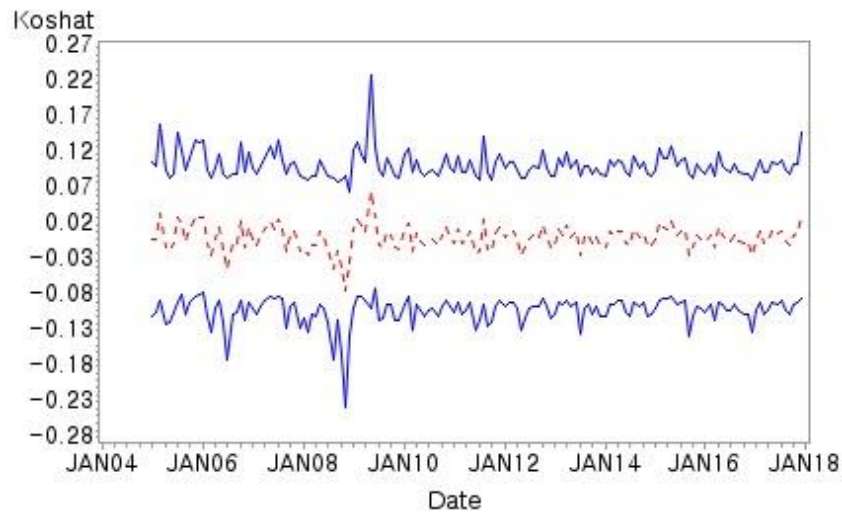

Fig. 4: $95 \%$ Confidence interval and forecast of log yield (KOSDAQ index)

\section{Conclusion}

The global financial market is experiencing high volatility due to the European fiscal crisis and the US economic slowdown. The volatility of the Korean financial market is also much higher than the usual financial crisis. The importance of estimating volatility for financial assets is increasing in terms of the minimization of uncertainty and pricing and risk management of financial assets. In this study, we estimated and forecasted the volatility of KRW/USD exchange rate from the macroeconomic point of view and KOSDAQ index from the microeconomic point of view by converting them into the log yields respectively. The models that analyze the characteristics of economic and financial time series data and predict the conditional volatility are various depending on the number and condition of parameters. In this study, both the KRW/USD exchange rate and the KOSDAQ index volatility estimation models were estimated to be based on the p-order autoregressive model, and the variance of error terms on the $\operatorname{ARCH}(q)$ model. Then it was confirmed that there was no autocorrelation and heteroscedasticity after testing the models. Therefore, the $\operatorname{AR}(p)-A R C H(q)$ model, which is the estimation model this study, is expected to be used as a basic research data for analyzing the volatility of financial assets and the ripple effects of financial market policies. And, since the rate of return is a concept of variance and is known to have a linear relationship with risk, we leave studies about ARCH-M model, which is a capital assets pricing model that maintains a linear relationship between risk and return, GARCH-M model, and VECM model, which is a model of the 
relationship between KRW/USD exchange rate and KOSDAQ index as future research tasks.

\section{Acknowledgement}

This Research was supported by Seokyeong University in 2018.

\section{References}

[1] Anderson T G and Bollerslev T (1998), Answering the skeptics: yes, standard volatility models do provide accurate forecasts, International Economic Review 39, 885-905.

[2] Akgiray V (1989), Conditional heteroskedasticity in time series of stock return evidence and forecasts, Journal of Business 62, 55-80.

[3] Jorion (1995), Predicting Volatility in the foreign exchange market, Journal of Finance 50, 507-528.

[4] Ghysels E, Santa-Clara P, Valkanov R (2003), Predicting volatility: the most out of return data sampled at different frequencies.

[5] Xiao and Aydemir (2007), Abdurrahman, Volatility Modelling and Forecasting in Finance, Knight J and Satchell S.(eds) (2007), Forecasting Volatility in the Financial Markets 3rd, Elsevier, pp.1-45.

[6] Kim T Y and Kwon O J (2001), Confidence interval forecast of exchange rate based on bootstrap method during economic crisis, Journal of Korean Data and Information Science Society 22, 895902.

[7] Kim B and Kim J (2012), Time series models for daily exchange rate data, The Korean Journal of Applied Statistics 26, 1-14.

[8] ] Kim C (2013), Forecasting and long memory exchange rate volatility, Review of Business \& Economics 26, 49-66.

[9] Jang D (2013), Exploratory data analysis for Korean daily exchange rate data with recurrence plots, Journal of Korean Data and Information Science Society 24, 1103-1112.

[10] Kwon D and Lee T (2014), Hedging effectiveness of KOSPI200 index futures throuth VECM-CC-GARCH model, Journal of Korean Data and Information Science Society 25, 1449-1466.

[11] ] Lee W and Chun H (2016), A deep learning analysis of the Chiness Yuan's volatility in the on share and offshore markets, Journal of Korean Data and Information Science Society 27, 327-335.

[12] Engle RF (1982), Autoregressive Conditional Heteroskedasticity with Estimates of the Variance of the United Kingdom Inflation, Econometrica 50, 987-1007.

[13] Bollerslev Tim (1986), Generalized Autoregressive Conditional Heteroskedasticity, Journal of Econometrics 31, 307-327.

[14] Ljung W K and Box G E P (1978), On a measure of lack of fit in time series model, Biometrika 65, 297-303.

[15] Engle RF, Granger CWJ, Kraft D (1984), Combining Competing Forecasts of Inflation Using a Bivariate ARCH Model, Journal of Economic Dynamics and Control 8, 151-165. 